\title{
Spectroscopy, Dynamics and Molecular Theory of Carbon Plasmas and Vapors
}

Advances in the Understanding of the Most Complex High-Temperature Elemental System 


\title{
Spectroscopy, Dynamics and Molecular Theory of Carbon Plasmas and Vapors
}

\author{
Advances in the Understanding of the Most \\ Complex High-Temperature Elemental System
}

Foreword by Sir Harold Kroto (Nobel Laureate, Chemistry, 1996)

\author{
editors \\ László Nemes \\ Hungarian Academy of Sciences, Hungary \\ Stephan Irle
oya University, Japan \\ Stephan Irle
Nagoya University, Japan
}


This page is intentionally left blank 


\title{
Published by
}

World Scientific Publishing Co. Pte. Ltd.

5 Toh Tuck Link, Singapore 596224

USA office: 27 Warren Street, Suite 401-402, Hackensack, NJ 07601

UK office: 57 Shelton Street, Covent Garden, London WC2H 9HE

\section{British Library Cataloguing-in-Publication Data}

A catalogue record for this book is available from the British Library.

\author{
SPECTROSCOPY, DYNAMICS AND MOLECULAR THEORY OF \\ CARBON PLASMAS AND VAPORS \\ Advances in the Understanding of the Most Complex \\ High-Temperature Elemental System \\ Copyright ( 92011 by World Scientific Publishing Co. Pte. Ltd. \\ All rights reserved. This book, or parts thereof, may not be reproduced in any form or by any means, \\ electronic or mechanical, including photocopying, recording or any information storage and retrieval \\ system now known or to be invented, without written permission from the Publisher.
}

For photocopying of material in this volume, please pay a copying fee through the Copyright Clearance Center, Inc., 222 Rosewood Drive, Danvers, MA 01923, USA. In this case permission to photocopy is not required from the publisher.

ISBN-13 978-981-283-764-6

ISBN-10 981-283-764-7

Printed in Singapore. 


\section{Foreword}

The spheroidal pure carbon cage molecules, the Fullerenes, and their elongated cousins, the Carbon Nanotubes, have opened up totally new and unexpected fields of scientific investigation which promise revolutionary advances in electrical, magnetic and tensile strength behaviour. These advances have catalysed fundamental research in Nanoscience and its strategic twin Nanotechnology $(\mathrm{N} \& \mathrm{~N})$ and in the next few decades this research promises to lead to completely new and revolutionary technologies with socio-economic impact analogous to the advances of the last half of the 20th century which has seen phenomenal breakthroughs in advanced materials applications, lasers, computers and the Internet etc. From a fundamental point of view N\&N is not really new at all but rather a new perspective on the way chemistry can impact other disciplines.

The fact that these breakthroughs are taking place at the beginning of the 21 st Century indicates that we still have a lot to learn - particularly about carbon! Interestingly from the point of view of this compendium, is the fact that the major breakthroughs in N\&N were stimulated by studies of the aggregation behaviour of small carbon species in the gas phase. There are many key areas of carbon behaviour that now need to be addressed and they are addressed in this volume. The articles promise to make a positive contribution to our understanding many problems and point the way for the next generation of researchers to successfully address many of these key issues: a) Studies of small carbon species from diatomic molecules to small carbon clusters in the gas phase are clearly vital if we are to understand carbon nanotube production processes. b) The only detailed way of studying such species is by spectroscopy and this allows the exploration of kinetic processes in plasmas and vapors. c) Modern lasers are ideal for spectroscopy and are also excellent for creating sample carbon vapors under controlled conditions. d) There is no doubt that we need an intrinsic understanding of the way that carbon clusters and subsequently forms condensed phase carbon nanostructures - in particular thin films. e) The fact that 
fullerenes are produced whenever soot is formed and furthermore is now being produced commercially by a combustion technique suggests that soot formation is still not that well understood. Indeed the fact that $\mathrm{C}_{60}$ was not detected by any soot researchers even though it is a key constituent combustion produced carbon aggregates provides significant food for thought! f) It is of course always important that theory and experiment move forward in a synergistic and complementary way so electronic and vibrational properties probed with modern computer simulation methods promise deep insights into carbon dynamics.

The articles in this volume highlight most of the important fundamental research areas as well as the technological challenges that must be confronted and overcome if the paradigm-shifting new approaches that carbon $\mathrm{N} \& \mathrm{~N}$ promises are to be realised. In particular the articles provide the information needed by students and specialists if they are to make progress in advancing our fundamental understanding and developing the applications of accurately nanostructured carbon materials.

\section{Sir Harold Kroto FRS}

The Florida State University

March 2011 


\section{Preface}

Nanotechnology and nanosciences are buzzwords of today. There are great expectations of brand new technologies and methods utilizing structures of size down to the molecular level, devices in a broad scale ranging from computers to medical devices and pharmaceuticals. The origin of such thoughts can probably be traced back to fiction novels written long ago, but perhaps it is not a mistake to date modern developments in the nanofields using the relatively recent discoveries of carbon nanostructures such as fullerenes, nanotubes, and graphenes. Nowadays there are new nanostructures built not from carbon but other chemical elements, such as silicon and gold to name just a few, and the domain of supramolecular organic chemistry is reaching far into the nanometer scale.

Nonetheless, nanostructures built purely and exclusively from carbon cover all possible dimensionalities, are the best studied nanscale materials around, and are among the most advanced candidates for application of nanotechnology in molecular electronics, sensors, and energy sciences. This book is a compendium of experimental and theoretical approaches for the study of spectroscopic and thermodynamic properties and the dynamics of carbon systems. The reader will soon discover that despite the chemical simplicity in terms of the atomic building blocks the formation as well as molecular and electronic structures of such nanomaterials are bewilderingly complex. We believe the present book will help the reader to appreciate the basic problems and will serve as thought provoker for research scientist and engineers in related fields.

This book is two-tiered, as it contains theoretical and experimental approaches. These are often intermingled as theoretical chapters contain references to experimental methods and the experimental chapters often contain theoretical considerations. The theoretical approaches covered in this book deal with the development and application of classical and quantum chemical potential energy functions governing structure formation and dynamics of carbon vapors. Fullerene and carbon 
nanotube formation, as well as carbon gasification reactions are the most prominent applications featured in this compendium. It is very important to gauge the validity of the potential energy surfaces; this can be achieved by comparison with high-level $a b$ initio benchmark calculations, as well as by simulating the evolution of IR and Raman spectra for systems containing more and more carbon atoms.

There are various possibilities for the experimenter to study carbon vapors and carbon plasmas. The majority of such experiments use spectroscopic methods. Electronic spectroscopy is a relatively simple and convenient tool, it is non-invasive and provides a multitude of physical and chemical data. Different chapters overlap in their coverage of spectroscopic applications, with most of the overlap being found in emission spectroscopic studies. Plasmas are very complicated and a special position is enjoyed by laser induced plasmas both in materials science applications and in basic spectroscopic research. By no means, however, are laser-induced plasmas unique to carbon vapors, one special and very important example is astronomy. We trust the knowledge concentrated in this book may help astronomers in their spectroscopic investigations of various stellar and interstellar objects (such as carbon stars and interstellar matter).

We believe this book will serve not only a specialist reading but also a support text for education in physical sciences at the College and University level. It will prove to students of science that elementary processes in high temperature atomic media are very good examples of complicated mechanisms that need fundamental knowledge, much of which is still open to studies and need fresh thought and innovative experimental approaches. There is absoutely no doubt that carbon nanostructures will play an important role for commercial applications of nanotechnology in the near future. We are pleased to release this book for the international readership and would like to thank World Scientific Publishers for the wonderful opportunity in its production.

\author{
László Nemes \\ Budapest, Hungary
}




\section{Contents}

Foreword $\quad$ V

Preface vii

$\begin{array}{ll}\text { Experimental } & 1\end{array}$

Chapter 1 Spectroscopy of Carbon Nanotube Production 3 Processes

B. A. Cruden

Chapter 2 Spectroscopic Studies on Laser-Produced Carbon

Vapor

K. Sasaki

Chapter 3 Kinetic and Diagnostic Studies of Carbon

Containing Plasmas and Vapors Using Laser

Absorption Techniques

J. Röpcke, A. Rousseau and P. B. Davies

Chapter 4 Spectroscopy of Carbon Containing Diatomic

Molecules

J. O. Hornkohl, L. Nemes and C. Parigger

Chapter 5 Optical Emission Spectroscopy of $\mathrm{C}_{2}$ and $\mathrm{C}_{3}$

Molecules in Laser Ablation Carbon Plasma N. A. Savastenko and N. V. Tarasenko

Chapter 6 Intra-Cavity Laser Spectroscopy of Carbon Clusters S. Raikov and L. Boufendi

Chapter 7 Dynamics of Laser-Ablated Carbon Plasma for Thin Film Deposition: Spectroscopic and Imaging Approach

R. K. Thareja and A. K. Sharma 
Chapter 8 Laser Spectroscopy of Transient Carbon Species in 255 the Context of Soot Formation

V. Nevrlý, M. Střižík, P. Bitala and Z. Zelinger

Chapter 9 Developing New Production and Observation

Methods for Various Sized Carbon Nanomaterials from Clusters to Nanotubes

T. Sugai

\section{Theoretical}

Chapter 10 Potential Model for Molecular Dynamics of Carbon

A. M. Ito and H. Nakamura

Chapter 11 Electronic and Molecular Structures of Small- and

Medium-Sized Carbon Clusters

V. Parasuk

Chapter 12 Vibrational Spectroscopy of Linear Carbon Chains

C.-P. Chou, W.-F. Li, H. A. Witek and

M. Andrzejak

Chapter 13 Dynamics Simulations of Fullerene and SWCNT Formation

S. Irle, G. Zheng, Z. Wang and K. Morokuma

Chapter 14 Mechanisms of Carbon Gasification Reactions

Using Electronic Structure Methods

J. F. Espinal, T. N. Truong and F. Mondragón

Index 